\section{Lieber cool als gesund}

E. Taverna ten zu Onanie und Spinatgenuss. Jugendliche brauchen Freiräume, müssen etwas selber verändern können. Für Urs Abt sind gegenwärtig die Kinder und Jugendlichen zu brav und zu konform. Die anwesenden zwei jungen Frauen sind Raucherinnen, der junge Mann ist ein Schulaussteiger, fährt Wildwasserkajak und auch Snowboard der wilderen Sorte. Gemeinsamer Tenor: «Mich kann man nicht überzeugen, ich tue was ich will.» Aus ihrer Sicht sind jene Jugendlichen problematisch, die keine Risiken eingehen, die Stillen, die nicht auffallen, bis es zu spät ist. Alle finden das entspannte, gleichberechtigte Gespräch mit Erwachsenen zentral. Bei denen orten sie die grössten Probleme, was auch ein gescheitertes Projekt im Freiamt bestätigt: Erwachsene sind festgefahren, kontaktgestört, sind desinteressiert und meist schlecht informiert. Was die drei gut formulierenden 19-, 20und 22jährigen vorbringen, überzeugt. Das Problem liegt bei der Altersgruppe der 187 anwesenden Erwachsenenvertreter, bei den Eltern, die kein Gespür haben und keine Gesprächskultur. Das haben auch die Fachleute gemerkt. Sie reagieren mit der Organisation des vermeintlich Selbstverständlichen, mit organisierten Gesprächsrunden, wie "Kinder reden mit» von Pro Juventute oder "Ciao" in der Romandie, mit Internetseiten und Hotlines. Die Präventionsarbeit richtet sich vermehrt an Eltern und Lehrer, an das Netzwerk "gesunder Schulen" und an die rund 100 Jugendverbände mit ihren über 450000 Mitgliedern.

Nachmittags werden drei Unternehmen vorgestellt, die Massstäbe setzen sollen: "Club minu», ein Programm des Migros Kulturprozents, das übergewichtigen Kindern und Jugendlichen helfen soll, "funtasy projects", das Jugendlichen beisteht, die selbstgewählten Lebensthemen als Projektideen umzusetzen und "Kreativ», ein Konzept für Jugendpolitik der Gemeinde Horgen, das die Lebensqualität der ansässigen Jugendlichen verbessern soll.

An kreativen Ideen mangelt es nicht. Die Gehschule der Pädagogik hat Fortschritte gemacht, bietet nettere Verpackungen als die mosaischen Steintafeln. Die WHO nennt Lebensfertigkeiten, "life skills», und Alltagskompetenzen als Präventionsziele. Pestalozzis «Kopf-, Herz- und Hand-Konzept» ist plötzlich wieder modern. Denn es scheint immer schwieriger, jung oder älter zu sein, immer schwieriger, das eigene Leben zu gestalten und zu meistern. Gefragt wäre eine Philosophie der Lebenskunst, eine Philosophie des Glücks in einer Welt zerfallender Normen, eine Gebrauchsanleitung der Lüste und Genüsse, das sokratische Gespräch mit dem Ziel des «Erkenne dich selbst" und des "Gebrauche deine Vernunft». Gesundheit wäre dann weit mehr als die gesteckten, medizinischen Ziele; doch davon war wenig die Rede. Die dürftige Gegenwart holt mich am Bahnhof Rüschlikon wieder ein. "Sei wie du bist», verkündigt das trendige Mineralwasserplakat, "trink was du willst." 